\title{
Role and uncertainty of foliar transfer in radiological impact assessments: State of the art and future actions
}

\author{
C. Madoz-Escande ${ }^{1}$, E. Leclerc ${ }^{2}$, C. Colle ${ }^{1}$ and P. Hurtevent ${ }^{1}$ \\ ${ }^{1}$ IRSNIDEI/SECRE, BP. 3, 13115 St. Paul-lez-Durance Cedex, France \\ ${ }^{2}$ ANDRA/DS-TR, French Agency for Radioactive Waste Management, Parc de la Croix \\ Blanche, 1 rue Jean Monnet, Châtenay-Malabry Cedex, France \\ e-mail: chantal.madoz-escande@irsn.fr; elisabeth.leclerc@andra.fr
}

\begin{abstract}
Sensitivity analyses have shown major role of foliar transfer for many radionuclides in the context of radiological impact assessments. A review of the published literature about foliar transfer focusing on translocation factors was carried out in order to constitute an updated database on one hand and to use the appropriate existing values of translocation parameters for modeling on the other. Translocation describes the distribution of radionuclides within the plant after foliar deposition and radionuclide absorption onto the surface of leaves. It mainly depends on elements and the plant growth stage. The collected data was derived from both in-field and greenhouse experiments. It was analysed to select those coming from a contamination simulating sprinkling irrigation or rain.

This work not only allowed us to carry out a diagnosis on the values themselves but also enabled us to ascertain missing data needs. In order to compensate for the lack of data on important radionuclides concerning radioactive waste $\left({ }^{129} \mathrm{I},{ }^{36} \mathrm{Cl},{ }^{79} \mathrm{Se}\right)$, experimental studies have been launched.
\end{abstract}

\section{CONTEXT AND DEFINITION}

Transfer of radionuclides to plants by sprinkling irrigation with contaminated water in standard agricultural conditions is usually modelled for radiological impact assessments of radioactive waste disposals. Ingestion exposures from irrigated agricultural land are often a few times higher than those of drinking water. The deposition of radionuclides on vegetation and soil represents the starting point for their transfer in the terrestrial environment and in food chains. Interception is the second parameter entering the model and is defined as the fraction of a radionuclide deposited by wet deposition that is initially retained by the vegetation. Although the activity retained is subsequently removed by weathering to the soil and, the fraction that is initially intercepted is a very important quantity in all radioecological models. This is because direct deposition may cause relatively high activity concentrations in feed and foods. Once deposited on vegetation, radionuclides are lost from plants due to removal by wind and rain, either through leaching or by cuticular abrasion. Translocation describes the systemic transport of radionuclides in the plant subsequent to foliar uptake. Translocation has no or very little influence on the long-term-fate of radioactivity in the environment, since it describes only the distribution of radionuclides within the plant subsequent to foliar deposition and absorption by the leaves. However, for estimating radionuclide concentrations in foods and for the assessment of doses to man, the systemic transport of radionuclides is a key issue. It is especially important for plants from which only specific parts are used as food or feed, such as cereals and potatoes. For plants that are used whole, such as leafy vegetables or maize silage, translocation is relevant only in that it may reduce the amount of activity that is lost by weathering processes.

Translocation is the phenomenon leading to the redistribution of a chemical substance, once it has been deposited on the aerial parts of a plant, to the other parts that have not been contaminated directly. The direct contamination of plants by radionuclides or toxic elements and their transfer from the foliage to edible parts depends on many physical, chemical and biological factors [1-4]. Physical factors include characteristics of the deposition regime and of the contaminants (rain duration, size of particles) and of the plant (foliage layout, leaf size and cuticular structure). Chemical factors include the speciation of 
the pollutant, water composition and cuticle composition [5, 6]. Biological factors are mainly associated with the vegetative cycle at the time of the foliar deposit [7-15]. Translocation partly reflects the mobility of an element within the plant. Its expression and, therefore its meaning, vary among authors. In this paper it's defined as the ratio between the activity of the edible part within $1 \mathrm{~m}^{2}$ of crops at harvest time $\left(\mathrm{Bq} \cdot \mathrm{m}^{-2}\right)$ and the foliage activity of $1 \mathrm{~m}^{2}$ of crops at the time of deposit $\left(\mathrm{Bq} \cdot \mathrm{m}^{-2}\right)$. This value is expressed as a percentage $(\%)$.

This study examines the translocation factors from published literature in order to constitute an updated database on one hand and to use the appropriate existing values of translocation parameters for modeling on the other. This work not only allowed us to carry out a diagnosis on the values themselves but also enabled us to ascertain missing data needs. With respect to the plant-growth stage at the time of deposit, only a few authors have been able to describe it precisely. They often limited themselves to mentioning the time between sowing and contamination or between contamination and harvesting, rather than the indication of a specific physiological stage. Comparing the results of different authors becomes, therefore, all the more difficult.

\section{CONSTITUTION OF THE DATABASE FOR TRANSLOCATION FACTOR VALUES ISSUED FROM LITERATURE REVIEW}

After examining the entire set of 682 values included in the database, 537 were selected as source data. The appreciation criteria for selecting the translocation-factor values to be used as the basis to determining a reference value and a corresponding range of potential variations rely mostly on the contamination mode of the whole plant. The selected values are those of a deposit that closely simulates a sprinkling irrigation. Hence, all values resulting from specific contamination processes (drop deposit on leaves or fruit), which are very distant from conditions likely to occur in agricultural ecosystems, were discarded. Other values were rejected either because they did not seem to apply only to translocation (direct contamination of a large fraction on the edible part) or because they were expressed in inappropriate units that could not be converted due to a lack of information on intermediate quantities. When the percentage was not mentioned directly in a cited publication, it was calculated on the basis of available data (biomass at deposit time and crop yield at harvest time, interception factor, etc.). The translocation-factor values have a dual origin: open-field experiments or greenhouse tests. For leaf vegetables and grass, translocation is not considered because of contamination mainly by direct deposition.

\section{RESULTS: TRANSLOCATION FACTORS TO VARIOUS PLANT ISSUED FROM LITERATURE}

\subsection{Overview}

The translocation-factor values are distributed as follows: $66 \%$ for grains, $19 \%$ for fruit and $15 \%$ for root vegetables. The majority of experiments dealt with $\mathrm{Cs}$ and $\mathrm{Sr}$ (Figure 1).

Some references are a bit old $([5,13] \ldots)$ and others come from more recent experiments $([16,17]$ ... ). Some other radionuclides, such as radioisotopes of $\mathrm{Mn}, \mathrm{Co}, \mathrm{Ru}$ and Ce provided between 20 and 40 translocation-factor values, with all plant types taken into account. For all isotopes taken into account, most translocation-factor values found in the literature concern wheat and barley.

\subsection{Cereals}

For cereal grains, after processing the selected values, it was possible to divide the vegetative cycle of the different crops under investigation into 5 stages (leaf development-tillering, stem elongation, earingflowering, grain growth and ripening). Experimental values for translocation factors were aggregated in 


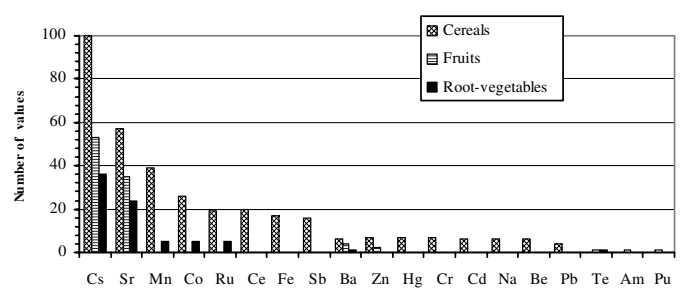

Figure 1. Distribution of the selected translocation-factor values (\%) in relation to radionuclides for the different types of plants.

Table 1. Best estimation (GM) of the translocation factor (\%) for some elements, for cereals grains (wheat, barley and rye) in relation to the vegetative stage at the time of contamination.

\begin{tabular}{|l|c|c|c|c|c|l|}
\hline $\begin{array}{l}\text { Vegetative } \\
\text { stage at the } \\
\text { time of } \\
\text { contamination }\end{array}$ & $\begin{array}{c}\text { Leaf } \\
\text { development- } \\
\text { tillering }\end{array}$ & $\begin{array}{c}\text { Stem } \\
\text { elongation }\end{array}$ & $\begin{array}{c}\text { Earing- } \\
\text { flowering }\end{array}$ & $\begin{array}{c}\text { Grain } \\
\text { growth }\end{array}$ & Ripening & References \\
\hline $\mathrm{Cs}$ & $0.6(21)$ & $4.6(21)$ & $6.1(15)$ & $5.5(11)$ & $2.7(11)$ & {$[1][7][9][10]$} \\
& $\{0.06-7.9\}$ & $\{0.5-24.3\}$ & $\{1.1-27.0\}$ & $\{1.1-27.1\}$ & $\{1.1-7.7\}$ & $\begin{array}{l}{[13][14][16]} \\
{[20][21]}\end{array}$ \\
\hline $\mathrm{Mn}$ & $0.3(3)$ & $2.1(8)$ & $2.3(6)$ & $2.0(6)$ & $1.0(6)$ & {$[1][7]$} \\
& $\{0.08-1.6\}$ & $\{0.2-10.7\}$ & $\{0.5-12.7\}$ & $\{0.5-8.6\}$ & $\{0.2-4.9\}$ & {$[10][16]$} \\
\hline $\mathrm{Co}$ & $0.5(5)$ & $1.0(3)$ & $2.0(4)$ & $2.8(4)$ & $1.5(3)$ & {$[1][8]$} \\
& $\{0.1-3.4\}$ & $\{0.2-4.6\}$ & $\{0.3-18.0\}$ & $\{0.3-29.0\}$ & $\{0.5-6.6\}$ & {$[10][16]$} \\
\hline $\mathrm{Fe}$ & $0.8(4)$ & $1.0(3)$ & $1.9(3)$ & $2.7(3)$ & $1.5(3)$ & {$[1][8]$} \\
& $\{0.7-1.2\}$ & $\{0.6-1.5\}$ & $\{1.3-2.6\}$ & $\{1.0-7.5\}$ & $\{0.4-9.2\}$ & {$[10]$} \\
\hline $\mathrm{Sr}$ & $0(2)$ & $0.1(13)$ & $0.4(5)$ & $2.0(6)$ & $1.2(8)$ & {$[1][7][10]$} \\
& & $\{0.008-1.6\}$ & $\{0.1-1.3\}$ & $\{0.6-8.5\}$ & $\{0.3-5.1\}$ & {$[13][14]$} \\
\hline $\mathrm{Sb}$ & $0.02(5)$ & $0.1(3)$ & $1.2(3)$ & $2.2(3)$ & $0.6(2)$ & {$[1][9]$} \\
& $\{0.002-0.6\}$ & $\{0.03-1.0\}$ & $\{0.3-5.2\}$ & $\{1.0-7.5\}$ & $\{0.3-1.3\}$ & {$[10]$} \\
\hline $\mathrm{Ce}$ & n.d. (0) & $0.1(8)$ & n.d. $(0)$ & $0.6(4)$ & $1.3(4)$ & {$[1][7]$} \\
& & $\{0.02-0.8\}$ & & $\{0.1-7.8\}$ & $\{0.3-6.0\}$ & \\
\hline
\end{tabular}

$\mathrm{x}=$ Geometric Mean; $(\mathrm{x})=$ number of selected values; $\{\mathrm{x}-\mathrm{x}\}=$ range of variation min - max from literature; $\mathrm{n} . \mathrm{d} .=$ no determinate.

relation to the vegetation stage corresponding to the state of the plant at the time of foliar contamination. For wheat, barley and rye, the values show that the maximum translocation value is reached when foliar contamination occurs i) about 45 days before harvesting (earing-flowering stage) for Cs and ii) about 30 days before harvesting (grain growth stage) for Sr. For rice, in spite of low value number [18], it seems that the maximum of translocation is reached when the contamination occurs at the grain-growth stage, whatever the radionuclide. The results of statistical analysis of raw data for cereals (associations of wheat, barley and rye on the one hand and rice on the other hand) are more thoroughly developed in [19], submitted. For wheat, barley and rye, some translocation factor values (geometric mean 'GM') of any radionuclides, as well as the numbers of selected values and the range (min-max) from literature are shown in Table 1.

\subsection{Root vegetables and tubers}

76 values of translocation factors to root-vegetables and tubers have been selected from the literature to be used in this database. The greater majority of the experiments concerned cesium and strontium and essentially potatoes and radishes (Figure 2). Some other radionuclides (Mn, Co, Ru, Te and Ba) have been investigated, but their exploitation is difficult due to the small amount of data. 
Table 2. Best estimation (GM) of the translocation factor values (\%) for root vegetables and tubers, whatever the plant growth stage.

\begin{tabular}{|l|c|c|c|l|}
\hline Element & $\begin{array}{c}\text { Translocation factor } \\
\text { geometric mean (\%) }\end{array}$ & $\begin{array}{c}\text { Number of } \\
\text { selected values }\end{array}$ & $\begin{array}{c}\text { Range of variation } \\
\text { min-max }\end{array}$ & References \\
\hline \multicolumn{5}{|c|}{ Root vegetables } \\
\hline $\mathrm{Cs}$ & 4.6 & 17 & $0.7-13$ & {$[13][14][18][21][22][23][24]$} \\
\hline $\mathrm{Sr}$ & 0.5 & 14 & $0.2-1.6$ & {$[13][14][18][22][23][24]$} \\
\hline $\mathrm{Mn}$ & 0.24 & 5 & $0.2-0.4$ & {$[18]$} \\
\hline $\mathrm{Co}$ & 8 & 5 & $4.9-12$ & {$[18]$} \\
\hline $\mathrm{Ru}$ & 0.15 & 5 & $0.1-0.4$ & {$[18]$} \\
\hline $\mathrm{Te}$ & 0.8 & 1 & & {$[22][24]$} \\
\hline $\mathrm{Ba}$ & 2.2 & 1 & \multicolumn{3}{|l|}{} \\
\hline \multicolumn{5}{|l|}{ Tubers } \\
\hline $\mathrm{Cs}$ & 11.6 & 23 & $1.3-46$ & {$[13][14][15][21][25]$} \\
\hline $\mathrm{Sr}$ & 0.1 & 9 & $0.02-0.5$ & {$[13][14][15][21][25]$} \\
\hline
\end{tabular}

Table 3. Best estimation (GM) of the translocation factor values (\%) for fruit.

\begin{tabular}{|l|c|c|c|c|}
\hline Element & $\begin{array}{c}\text { Translocation factor } \\
\text { geometric mean }(\%)\end{array}$ & $\begin{array}{c}\text { Number of } \\
\text { selected values }\end{array}$ & $\begin{array}{c}\text { Range of variation } \\
\text { min-max }\end{array}$ & References \\
\hline $\mathrm{Cs}$ & 4.6 & 53 & $0.1-29$ & {$[5][12][13][17][21-23][25-37]$} \\
\hline $\mathrm{Sr}$ & 0.44 & 35 & $0.01-12.1$ & {$[5][12][13][17][21-23][25-37]$} \\
\hline $\mathrm{Ba}$ & 0.13 & 4 & $0.04-1.6$ & {$[17][22]$} \\
\hline $\mathrm{Zn}$ & 4.3 & 2 & $2.6-7$ & {$[26]$} \\
\hline $\mathrm{Am}$ & 0.0005 & 1 & & {$[38]$} \\
\hline $\mathrm{Pu}$ & 0.0003 & 1 & & {$[38]$} \\
\hline
\end{tabular}

Because of the small amount of raw data and also because the vegetative stage was not always well specified, the values of translocation factor were combined for all the vegetative cycle. Whatever the plant growth stage, the geometric mean and the variation range of translocation factors in root vegetables (radishes, beets, carrots, swedes and turnips) and tubers (potatoes) are reported in Table 2.

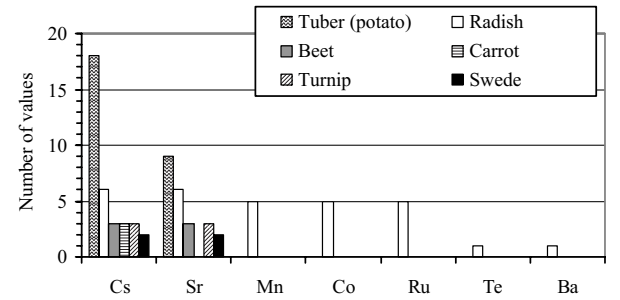

Figure 2. Distribution of translocation-factor values $(\%)$ in relation to radionuclides for the different types of root vegetables.

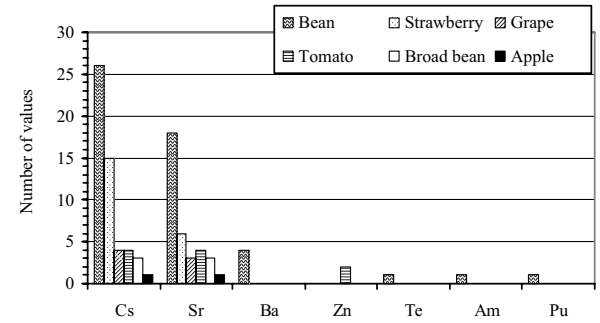

Figure 3. Distribution of translocation-factor values $(\%)$ in relation to radionuclides for the different types of fruit.

\subsection{Fruit}

97 values of translocation factors to fruits have been removed from the literature and have been selected to be used in this review. The greater majority of the experiments dealt with cesium (55\%) and strontium $(36 \%)$ (Figure 3). Some other radionuclides ( $\mathrm{Ba}, \mathrm{Zn}, \mathrm{Te}, \mathrm{Am}$ and $\mathrm{Pu}$ ) have been investigated, but the exploitation of the experimental results is difficult due to the small amount of data. Because of the 
small amount of raw data for some fruit species and also because the available data was of the same order of magnitude, the raw data was aggregated by radionuclide whatever the type of fruit considered (beans, broad beans, tomatoes, strawberries, grapes and apples) and the vegetative stage at the time of contamination. For each radionuclide, the results of the translocation factors (corresponding to the geometric mean of the values obtained during the vegetative cycle) are shown in Table 3 .

\section{CONCLUSIONS OF THE LITERATURE REVIEW}

This review gives the state of knowledge about the translocation factor values defined as the ratio between total activity in the edible parts of the plant and activity retained on foliage (percentage). The analysis of the scientific literature concerning this parameter of transfer highlighted an important lack of knowledge. The interaction of translocation and plant development in particular is poorly investigated for many crops and radionuclides. Furthermore, there is practically no data on translocation factors in chronic contamination situations simulating sprinkling irrigations distributed throughout the vegetative cycle of a crop. Also, the majority of the available data relates to Cs and Sr. Radioisotopes of some other elements (Mn, Co, Fe, Ru, Sb, Ce, Ba, Zn, Te, Hg, Cr, Na, Cd, Be and Pb) have been investigated, but the data is far from sufficient to obtain reliable values for all the plant types. Moreover, some authors do not make a distinction between plant types and recommend a single default value whatever the element and plant type. Data given without growth stage indication should be used with caution indicating the wide range of associated uncertainty. It would also be advisable to be able to differentiate the various types of fruits.

In order to supplement the current lack of knowledge on translocation, undertaking further research through experimental investigations is essential.

\section{PROSPECTS: PROTOCOL DEVELOPED FOR NEXT EXPERIMENTAL STUDIES}

The detailed literature review has shown a lack of data for a lot of radionuclides especially for those which are major contributors to radioactive waste disposals radiological impact assessments.

Thanks to the Chernobyl Exclusion Zone facilities developed by UIAR, experiments in open field conditions will be launched to obtain translocation factor values especially for chlorine-36, iodine-129 and Se-79. These experiments aim to simulate a sprinkling irrigation with contaminated water in standard agricultural conditions. Four main parameters influencing variations of the translocation factor values will be taken into account: vegetal species, the radionuclides themselves, the contamination mode and the physiological stage during which it occurs.

The model plants chosen belong to four great human consumption groups: a cereal (Triticum aestivum), a root vegetable (Raphanus sativus L.), a fruit vegetable (Phaseolus vulgaris L.) and a tuber (Solanum tuberosum L.). Concerning chemical species of used isotopes, chloride, iodide and selenite have been identified as the main abundant forms in a medium irrigation water. The contamination will be simultaneous for the whole of elements according to 2 modalities: a wet punctual unique foliar deposit simulating an accident and a wet multiple foliar deposit simulating chronic contamination. It will be performed during identified sensitive phenological stages of plants (e.g. flowering) according to the vegetal specie, their canopy architecture spread and position of edible parts owing to their influence on interception and detection limits for measurement. Contamination dates will be the same for both contamination modalities for a considered vegetal species.

As the objective of these experiments is to obtain "pure" translocation factors, we shall avoid soil contamination from contamination stage until harvest because of the importance of root transfer factors for chloride [39] and for selenite [40], but also rain washing of leaf surfaces during cultural cycle. That's why soil protection and rain protection features respectively under and above canopy will be built with an adapted design permitting recovery of rain amounts for irrigation and allowing 
daylight spectrum reaching the canopy (cf. [13]). In order to avoid an increase of variability we shall use for all cultures a same soil with adapted fertilization rate according to the needs of each and standardized agronomical practises will be maintained constant. As no preventive or curative treatment can be spread because of interferences with foliar transfer, characteristics of soil participate also in maintaining a good plant health status through its draining potential. Furthermore, rotation of cultures and a survey of physiological state through the Leaf Area Index will be done. This last parameter is also of key importance in calculating the interception factor. Acquired data sets for interception-LAI and biomass-LAI relations will be implemented in existing databases for modelling. Control of daily climatic parameters (temperatures and rain amounts) will be performed thanks to a meteorological station established in the CEZ (3 km nearby).

\section{References}

[1] Aarkrog A. Translocation of radionuclides in cereal crops. Ecological aspects of radionuclides releases. Oxford Blackwell scientific Publishers (1983): 81-90.

[2] Hoffman F. O., Thiessen K. M., Rael R. M. Comparison of interception and initial retention of wet-deposited contaminants on leaves of different vegetation types. Atmospheric Environment (1995) 29 (15): 1771-1775.

[3] Kinnersley R. P. and. Scott L. K Aerial contamination of fruit through wet deposition and particulate dry deposition. Journal of Environmental Radioactivity (2001) 52 (2-3): 191-213.

[4] Muller H. and Pröhl G. Ecosys-87: A dynamic model for assessing radiological consequences of nuclear accidents. Health Physics (1993) 64 (3): 232-252.

[5] Bukovac M. J., Wittwer S. H., Tukey H. B. Above ground plant parts as a pathway for entry of fission products into the food chain with special reference to 89-90Sr and 137Cs. In: Radioactive fallout, soils, plants, foods, man. E. Fowler, Ed. Elsevier Press New York, (1965): 82-109.

[6] Franke W. Mechanisms of foliar penetration of solutions. Ann. Rev. plant phys. (1967) 18, 281-300.

[7] Aarkrog A. On the direct contamination of rye, barley, wheat and oats with Sr-85, Cs-134, Mn-54 and Ce141. Radiation Botany (1969) 9: 357-366.

[8] Aarkrog A. and Lippert J. Direct contamination of barley with Cr-51, Fe-59, Co-58, Zn-65, Hg-203 and Pb-210. Radiation Botany (1971) 11: 463-472.

[9] Aarkrog A. Direct contamination of barley with Be-7, Na-22, Cd-115, Sb-125, Cs-134 and Ba-133. Risoe report No. 256. Danish Atomic Energy Commission (1972): 163-175.

[10] Aarkrog A. Radionuclide levels in mature grain related to radiostrontium content and time of direct contamination. Health Physics (1975) 28: 557-562.

[11] Carini F. Radionuclides in plants bearing fruit: an overview. JER (1999) 46(1): 77-97.

[12] Carini F., Green N., Spalla S. Radionuclides in fruit systems: A review of experimental studies. Science of The Total Environment (2006) 359(1-3): 188-193.

[13] Middleton L. J. Absorption and translocation of strontium and caesium by plants from foliar sprays. Nature (1958) 181: 1300-1303.

[14] Middleton L. J. Radioactive strontium and caesium in the edible parts of crop plants after foliar contamination. Inter. J. Rad (1959) 4: 387-402.

[15] Middleton L. J. and. Squire H. M Further studies of radioactive strontium and caesium in agricultural crops after direct contamination. Int. J. Rad. Biol. (1963) 6(6): 549-558.

[16] Shaw G., Minski M. J., Bell J. N. B. Retention, loss and translocation of radionuclides applied to foliar surfaces of wheat. Environmental and Experimental Botany (1992) 32(4): 391-404.

[17] Madoz-Escande C., Henner P., Bonhomme T. Foliar contamination of Phaseolus vulgaris with aerosols of $137 \mathrm{Cs}, 85 \mathrm{Sr}, 133 \mathrm{Ba}$ and $123 \mathrm{mTe}$ : influence of plant development stage upon contamination and rain. JER (2004) 73(1): 49-71. 
[18] Choi Y. H, Lim K. M., Yu D., Park H. G., Choi Y. G., Lee C. M. Transfer pathways of 54Mn, $57 \mathrm{Co}, 85 \mathrm{Sr}, 103 \mathrm{Ru}$ and $134 \mathrm{Cs}$ in rice and radish plants directly contaminated at different growth stages. Ann. of Nuc. Ener. (2002) 29(4): 429-446.

[19] Colle C., Madoz-Escande C., Leclerc E. Foliar transfer into the biosphere: review of translocation factors to cereals grains, JER, Special issue for AIEA/EMRAS program/Revision of Tech. Report Series n ${ }^{\circ} 364$, submitted.

[20] Gerdung S., Pöllot M., Fischer P., Grillmaier R. E., Müller P. Contamination of wheat, rye, and potatoes by foliar application of 134Cs. Journal of Radioanalytical and Nuclear Chemistry (1999) 240(2): 451-454.

[21] Voigt G., Pröhl G., Müller H. Experiments on the seasonality of the cesium translocation in cereals, potatoes and vegetables. Radiation and Environmental Biophysics (1991) 30(4): 295-303.

[22] Madoz-Escande C. and Santucci P. Weather-dependent change of cesium, strontium, barium and tellurium contamination deposited as aerosols on various cultures. JER (2005) 84(3): 417-439.

[23] Baeza A., Paniagua J. M., Rufo M., Sterling A., Barandica J. Radiocaesium and radiostrontium uptake by turnips and broad beans via leaf and root absorption. Applied Radiation and Isotopes (1999) 50(3): 467-474.

[24] Madoz-Escande C. Bonhomme T., Poncet-Bonnard D. Foliar contamination of plants with aerosols of $137 \mathrm{Cs}$, 85Sr, 133Ba and 123mTe: Influence of rain. Radioprotection (2005) 40(Suppl.1): S421-S427.

[25] Delmas J., Disdier R., Grauby A., Bovard P.. Radiocontamination expérimentale de quelques espèces cultivées soumises à l'irrigation par aspersion. In: Actes Ie Symp. Intern. de Radioéc., C.E.N. Cadarache, 8-12 sept. 1969: 707-729.

[26] Brambilla M., Fortunati P., Carini F. Foliar and root uptake of $134 \mathrm{Cs}, 85 \mathrm{Sr}$ and $65 \mathrm{Zn}$ in processing tomato plants (Lycopersicon esculentum Mill.). JER (2002) 60(3): 351-363.

[27] Carini, F., Anguissola Scotti I., Montruccoli M., Silva S. 134Cs foliar contamination of vine: translocation to grapes and transfer to wine. In M. Gerzabek (Ed) Internat. Symp. of Radioec. 10 years terrest. Radioecol. research follow. the Chernobyl accident. Vienna, Aust.: Aust. Soil Science Soc. and Fed. Envir. Agency. (1996): 163-169.

[28] Carini F. and Lombi E. Foliar and soil uptake of $134 \mathrm{Cs}$ and $85 \mathrm{Sr}$ by grape vines. Science of the Total Environment (1997) 207(2-3): 157-164.

[29] Carini F., Brambilla M., Mitchell N., Ould-Dada Z. Cesium-134 and Strontium-85 in Strawberry Plants following Wet Aerial Deposition. Journal of Environmental Quality (2003) 32(6): 2254-2264.

[30] Macacini J. F., De Nadai Fernandes E. A., Taddei M. H. T. Translocation studies of 137Cs and 90Sr in bean plants (Phaseolus vulgaris): simulation of fallout. Environmental Pollution (2002) 120(1): 151-155.

[31] Oncsik M. B., Eged K., Kis Z., Kanyar B. A validation study for the transport of 134 Cs to strawberry. JER (2002). 61(3): 319-329.

[32] Madoz-Escande C., Colle C., Adam C. Evolution of cesium and strontium contamination deposited on vines. Radioprotection Colloques (2002). 37 C1: 515-520.

[33] Brambilla M., Strebl F., Carini F., Gerzabek M. Ventomod: a dynamic model for leaf to fruit transfer of radionuclides in processing tomato plants (Lycopersicon esculentum Mill.) following a direct contamination event. JER (2003) 65(3): 309-328.

[34] Carini, F. and Bengtsson G. Post-deposition transport of radionuclides in fruit. JER (2001) 52 (2-3): 215-236.

[35] Koranda, J. J. and Robison W. L. Accumulation of radionuclides by plants as a monitor system. Environmental Health Perspectives (1978). 27: 165-179.

[36] Ould-Dada Z., Carini F., Eged K., Kis Z., Linkov I., Mitchell N.G., Mourlon C., Venter A. Radionuclides in fruit systems: Model prediction-experimental data intercomparison study. Science of The Total Environment (2006) 366 (2-3): 514-524. 
[37] Ould-Dada Z., Carini F., Mitchell N.G. A model testing study for the transfer of radioactivity to fruit. JER (2003) 70(3): 207-221.

[38] Cataldo D. A., Garland T. R., Wildung R. E., Thomas J.M.. Foliar absorption of transuranic elements: Influence of physicochemical form and environmental factors. JEQ (1980) 9(3): 364-369.

[39] Kashparov V., Colle C., Zvarich S., Yoschenko V., Levchuk S., Lundin S. Soil-to-plant halogens transfer studies 2. Root uptake of radiochlorine by plants. JER (2005) 79(3): 233-253.

[40] Wan H.F., Mikkelsen R.L., Page A.L. Selenium uptake by some agricultural crops from central California soils. JEQ, (1988) 17(2): 269-272. 